\title{
Design of a 10 Credit Masters Level Assistive Technologies and Universal Design Module
}

\author{
Mike Wald \\ A School of Electronics and Computer Science \\ University of Southampton, United Kingdom \\ M.Waldesoton.ac.uk
}

\begin{abstract}
The paper reports on the design and evaluation of a 10 credit module that has been designed and taught for the first to 35 full time Computer science and software engineering Masters students.
\end{abstract}

\section{Introduction}

A 10 credit module has been designed and taught for the first time by the author to 35 full time Computer science and software engineering Masters students. The course was taught through eleven 45 minute sessions involving guest lecturers as well as theoretical and practical online tasks with course material made available online.

\section{Course Syllabus and Structure}

The Aims of the module were:

- To understand the role of Assistive technologies in achieving universal design

- $\quad$ To explore the relationship between accessibility and usability

- To prepare students to engage in research and development in assistive technologies and universal design

The Learning Outcomes were that having successfully completed the module, students will be able to demonstrate knowledge and understanding of:

- Models of disability

- Definitions of Assistive Technology and Universal Design

- $\quad$ Relevant Legislation and Accessibility and Usability Standards

- The interdisciplinary approach to design, research, evaluation

- $\quad$ Assessment for assistive technology and universal design

- Sources of information about Current research in assistive technology and universal design

and will be able to: 
- $\quad$ Analyse the relationship between accessibility and usability and justify a case regarding the extent universal design should depend on assistive technologies Evaluate how your knowledge, skills and interests would be best applied in interdisciplinary research and development in assistive technologies and universal design

- $\quad$ Evaluate usability and accessibility of technologies

- Identify a role in interdisciplinary research, development and design of assistive technologies

- $\quad$ Analyse, summarise and present up-to-date research publications

- Communicate findings in a variety of modes

Topics Covered included:

- $\quad$ Case for universal design (Business, Legislation, Moral, self interest)

- Models of disability

- $\quad$ Ethical research issues

- Assistive Technologies and Universal Design

- Accessibility and Usability Standards

- $\quad$ Assistive Technology Assessment and Evaluation

- Involving users in research design and evaluation

- $\quad$ Research in assistive technologies and universal design

Teaching methods included lectures to present concepts and theory; Seminars to explore research issues and workshops and supported tasks to provide practical experience. Learning activities included presenting analysis of current research issues in seminars, usability studies and accessibility evaluation in workshops and online tasks, directed reading of selected of articles on lecture topics, creation of accessible and usable website and online oral presentation. Feedback and student support during module study included: Seminar feedback, Workshop support, feedback on assignments, peer-review

The relationship between the teaching, learning and assessment methods and the planned learning outcomes was:

- $\quad$ Lectures present concepts and theory

- Seminars explore research issues

- Workshops facilitate usability and accessibility evaluations

- The assessment provides an opportunity to demonstrate ability to evaluate and create a usable and accessible website and communicate findings through a website, in writing and orally. Students can work in groups or individually on the web site.

- The students will be involved in the assessment of report, website and oral presentation 


\section{Course Resources}

Extensive Course Resources (including links to video audio recordings, disability simulations, web sites, documents etc.) were categorised and organised and provided for students to carry out tasks out of class contact time. Books were also suggested as background Resources.

\section{Methods of assessment}

Written report: (70\% contribution to final module mark): Write a 2000 word report evaluating two software applications and two websites for accessibility and usability. Give examples of the assistive technologies that may be required for users to access them and any problems users may still have. Validate/check the XHTML and CSS and Accessibility status and browser compatibility and provide screen print outs as evidence. Detailed Criteria for report and \% contribution to final module mark:

- Software accessibility evaluation 5\%

- Software usability evaluation 5\%

- Web site accessibility evaluation $5 \%$

- Web site designing to standards evaluation 5\%

- Web site usability evaluation 5\%

- Web site browser and operating system compatibility evaluation 5\%

- Assistive technology description and analysis $25 \%$

- Presentation of report and ability to communicate appropriately in writing $15 \%$

Website: (20\% contribution to final module mark): Create an accessible website that presents a summary of the report's findings. Validate/check the XHTML and CSS and Accessibility status and browser compatibility and provide evidence as part of the website. Students were asked also to rate each other's websites and oral presentations by emailing marks out of ten to me and I revealed the favourite websites at the end of the course. Detailed Criteria for website design and implementation and \% contribution to final module mark were:

- Web site accessibility demonstrated and tested $3 \%$

- Designing to standards demonstrated and tested $3 \%$

- Web site usability demonstrated and evaluated $3 \%$

- Browser and Operating System compatibility evaluated and demonstrated $3 \%$

- Copyright $\&$ any legal \& ethical issues addressed $2 \%$

- Structure and Content and Design appropriate $6 \%$ 
Online Oral presentation: (10\% contribution to final module mark) Create a 3 minute accessible web-based oral presentation with visual aids presenting a summary of the report's findings. Detailed Criteria for oral presentation and $\%$ contribution to final module mark:

- Presentation accessibility demonstrated and tested $4 \%$

- Browser and Operating System compatibility evaluated and demonstrated $3 \%$

- Content and Design appropriate $3 \%$

\section{Online Discussions}

Students could send comments to the Asynchronous discussion board about the issues raised in a range of out of class tasks. The Module tutor responded to these as appropriate. Examples include:

this series of video clips was a bit scary as I consider myself an able-bodied person and it was somewhat disturbing to think that I could possibly be among those who ostracize disabled people.

Yes, I felt the same. I found the series of videos very powerful and it really brought it home just how people with disabilities must feel at times. The video was very cleverly made to help everyone understand how even just small comments which may seem harmless may affect other people.

Useful bit of information. I'm almost ashamed to admit that some $10+$ yrs ago I would have referred to someone as being retarded

\section{Evaluations}

Students gave an average rating for the module of 4.5 out of 5 for the usefulness, clarity, interest, content, teaching and organisation. Comments were universally very positive but 2 out of the 37 students would have liked some more direction and structured tasks to follow rather than investigating the wide range of resources provided.

\section{Conclusion}

The able self-motivated Master's level students found the module very useful and interesting and the majority enjoyed the flexibility of selecting from the wide range of resources and tasks provided.. 